\title{
Pinch Analysis of Methane Derived Methanol Plant Using HINT Software
}

\author{
John Philia, Jedy Prameswari, and Widayat ${ }^{*}$ \\ Department of Chemical Engineering, Universitas Diponegoro, Semarang, 50275
}

\begin{abstract}
Methane is a highly potent greenhouse gas which contributes to the pressing global warming issue in the world. Methanol derived from methane was one of the solutions to prevent the escalating greenhouse effect. However, the process was energy intensive and hence pinch technology was used to optimize the heat efficiency in the process. This study aims to determine the optimum $\Delta \mathrm{T}_{\min }$ indicated with lowest total cost via HINT software. Results shown that the optimum heat exchanger configuration was obtained by network with $\Delta \mathrm{T}_{\min } 10 \mathrm{~K}$, with minimum operating and capital cost of $\$ 2,729,590 /$ year and $\$ 579,129,590 /$ year respectively.*
\end{abstract}

\section{Introduction}

Climate change and global warming are persistent worldwide issues for the past decade. One of the factors for the occurrence is the greenhouse effect, which is a process that occurs when the gases in the atmosphere trapped the sun's heat [1]. Methane is included as one of the gases, with 84 times more greenhouse potential compared to carbon dioxide [2]. About $25 \%$ of the manmade global warming was caused by methane emissions, largely due to hydrocarbon combustion engines including natural gas and LPG fed engines, gas oil fired furnace and power plants [3]. To combat the rising global warming matter, methane could be converted to methanol, which hold various application in products, namely solvents, detergents, paints, antifreeze, acetic acid and formaldehyde. Moreover, methanol could also be used as liquid fuel or raw material for gasoline and olefin production [4]. Methanol production plants are generally considered as one of the petrochemical industries requiring intensive energy. This is due to the fact that in the whole process, including the feed preparation, natural gas desulfurization, synthesis gas production, feed gas compression, reactions and product distillation consumed huge amount of energy through heating, cooling and shaft works. Hence, researches to reduce the intensive energy consumption have been conducted, and one of the applicable solutions was to optimize the heat energy flowing in the system through pinch analysis [5]. Pinch analysis is a systematic method which optimizes the energy usage in process plants consisting of several techniques, namely heat flow analysis, energy target establishment, inefficiencies identification and process improvement determination [6,7]. The objective of this work was to determine which heat exchanger

\footnotetext{
* Corresponding author: widayat@live.undip.ac.id
} 
configuration with different $\Delta \mathrm{T}_{\text {min }}(10,15$ and $20 \mathrm{~K})$ would give the optimum heat efficiency indicated by the lowest cost of operation.

\section{Case Study}

In this study, the methanol synthesis plant design (Figure 1) was taken from Kijevcanin et al. [8]. The basic stream data of methanol synthesis was presented in Table 1. This process included 10 hot streams and 5 cold streams.

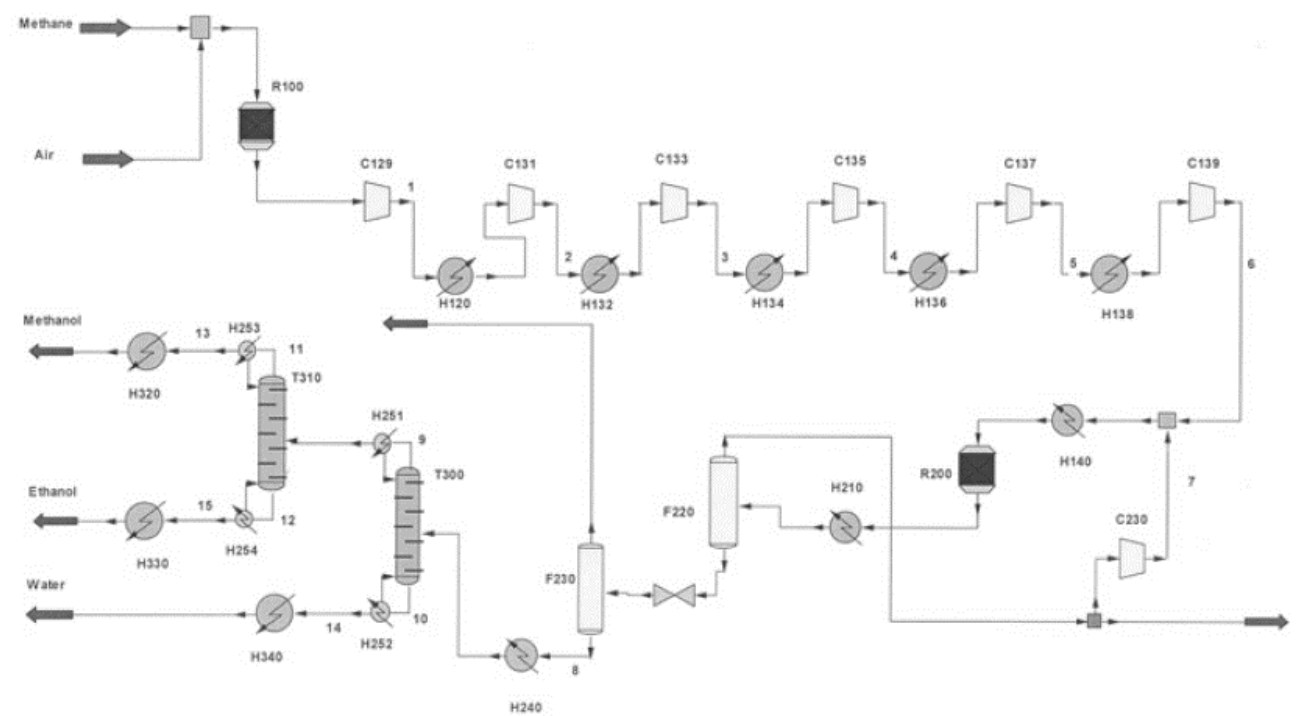

Fig. 1. Methanol plant design 
Table 1. Stream table

\begin{tabular}{ccccc}
\hline Stream & Ts $(\mathbf{K})$ & Tt $(\mathbf{K})$ & $\mathbf{H}(\mathbf{k W})$ & $\mathbf{m . C p}(\mathbf{k W} / \mathbf{K})$ \\
\hline 1 & 424.3 & 120 & -1521.5 & 5 \\
2 & 342.1 & 120 & -1110.5 & 5 \\
3 & 342.2 & 120 & -1111 & 5 \\
4 & 343.1 & 160 & -933.81 & 5.1 \\
5 & 403.1 & 210 & -1004.12 & 5.2 \\
6 & 37.7 & 450 & 1896.58 & 4.6 \\
7 & 14.5 & 70 & 227.55 & 4.1 \\
8 & 62 & 62 & -1108 & - \\
9 & 98.9 & 98.9 & 1126 & - \\
10 & 60.6 & 60.6 & -1869 & - \\
11 & 76.4 & 76.4 & 1866 & - \\
12 & 60.6 & 30 & -76.5 & 2.5 \\
13 & 98.9 & 30 & -75.79 & 1.1 \\
14 & 76.4 & 30 & -13.92 & 0.3 \\
15 & 349.7 & 450 & 1925.76 & 19.2 \\
\hline
\end{tabular}

\subsection{Heat exchanger network design}

The design of the heat exchanger network (HEN) usually started at the pinch, since this is the most constrained region. The acceptable minimum temperature difference is called the pinch temperature. Pinch divided the entire temperature interval into two regions, above the pinch which contain the hot utility region and below pinch which belonged to the cold utility region [9]. Furthermore, to design a HEN, several feasibility criteria should also be followed, namely stream population and heat capacity flowrate difference. Stream population stated that at the hot region of the pinch, the number of cold streams must be higher or equal to the number of hot streams available $\left(\mathrm{N}_{\mathrm{cou}}>\mathrm{N}_{\text {hax }}\right.$ ). While at the cold region of the pinch, the opposite was expected $\left(\mathrm{N}_{\mathrm{bx}}>\mathrm{N}_{\mathrm{ou}}\right)$. The heat capacity flowrate difference also stated that at the hot region of the pinch, the heat capacity flowrate of the cold stream must be higher than that of the hot stream $\left(\mathrm{Cp}_{\mathrm{w} \text { }}>\mathrm{Cp}_{\mathrm{na}}\right)$, and the opposite was true for the cold region of the pinch $\left(\mathrm{Cp}_{\mathrm{wot}}\right.$ $\left.>\mathrm{Cp}_{\mathrm{owi}}\right)[10]$.

In designing a HEN, the most helpful representation is the grid diagram introduced by Linhoff and Flower (1978). The streams were drawn as horizontal lines, with the high temperature on the left-hand side and the hot streams at the top. Heat exchanger matches are represented by two circles joined together with a vertical line. Grid diagram represents the counter current nature of the heat exchange, making it easier to check the feasibility of exchange temperature [11]. The HEN diagrams of the methanol synthesis illustrated in Figure 2-4 was obtained by HINT, a non-commercial software for HEN designing. The minimum temperature difference $\left(\Delta \mathrm{T}_{\text {min }}\right)$ gave some implications to the energy and cost efficiency. In this study, in order to determine the optimum $\Delta \mathrm{T}_{\text {min }}$, variations of said value was made to be 10,15 and $20 \mathrm{~K}$. 


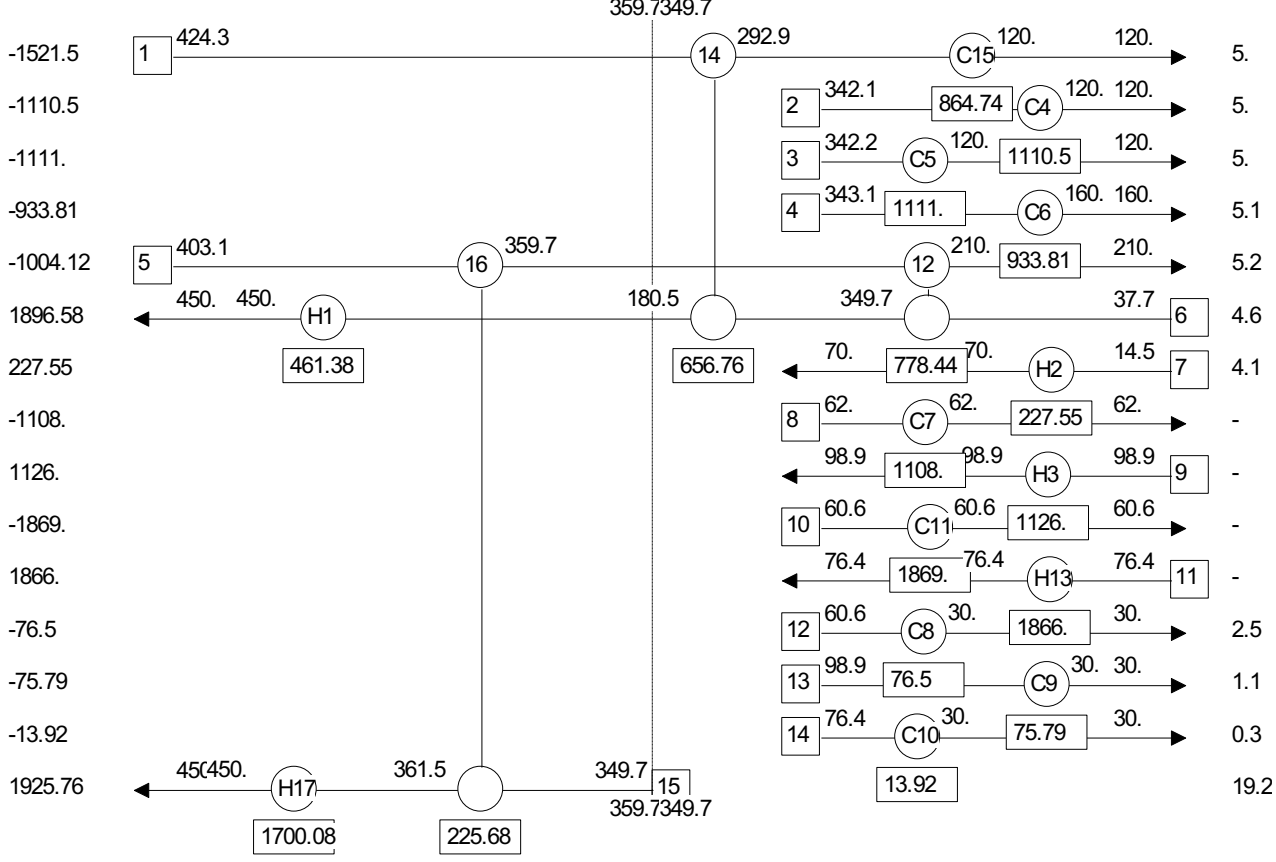

Fig. 2. HEN of methanol synthesis with $\Delta \mathrm{T}_{\min } 10 \mathrm{~K}$

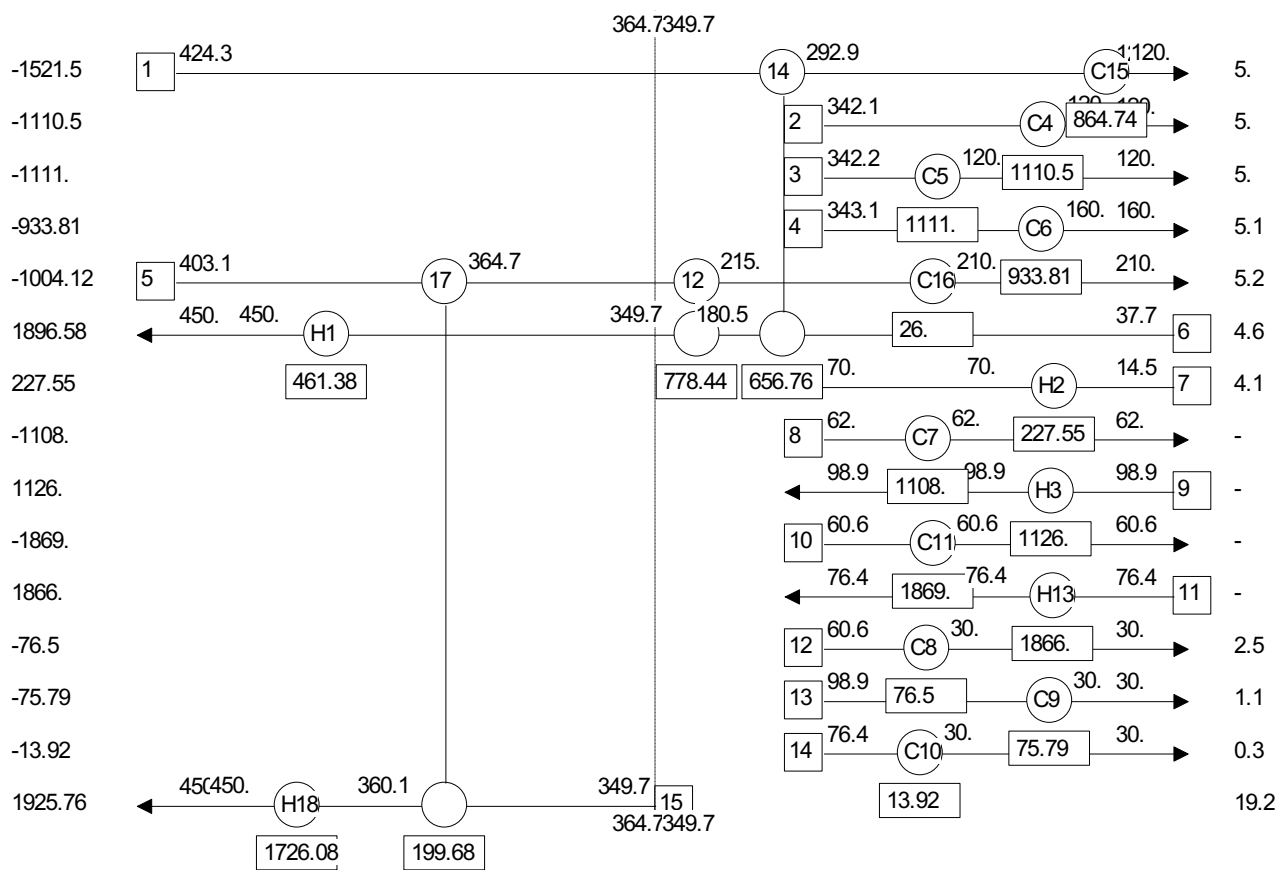

Fig. 3. HEN of methanol synthesis with $\Delta \mathrm{T}_{\min } 15 \mathrm{~K}$ 


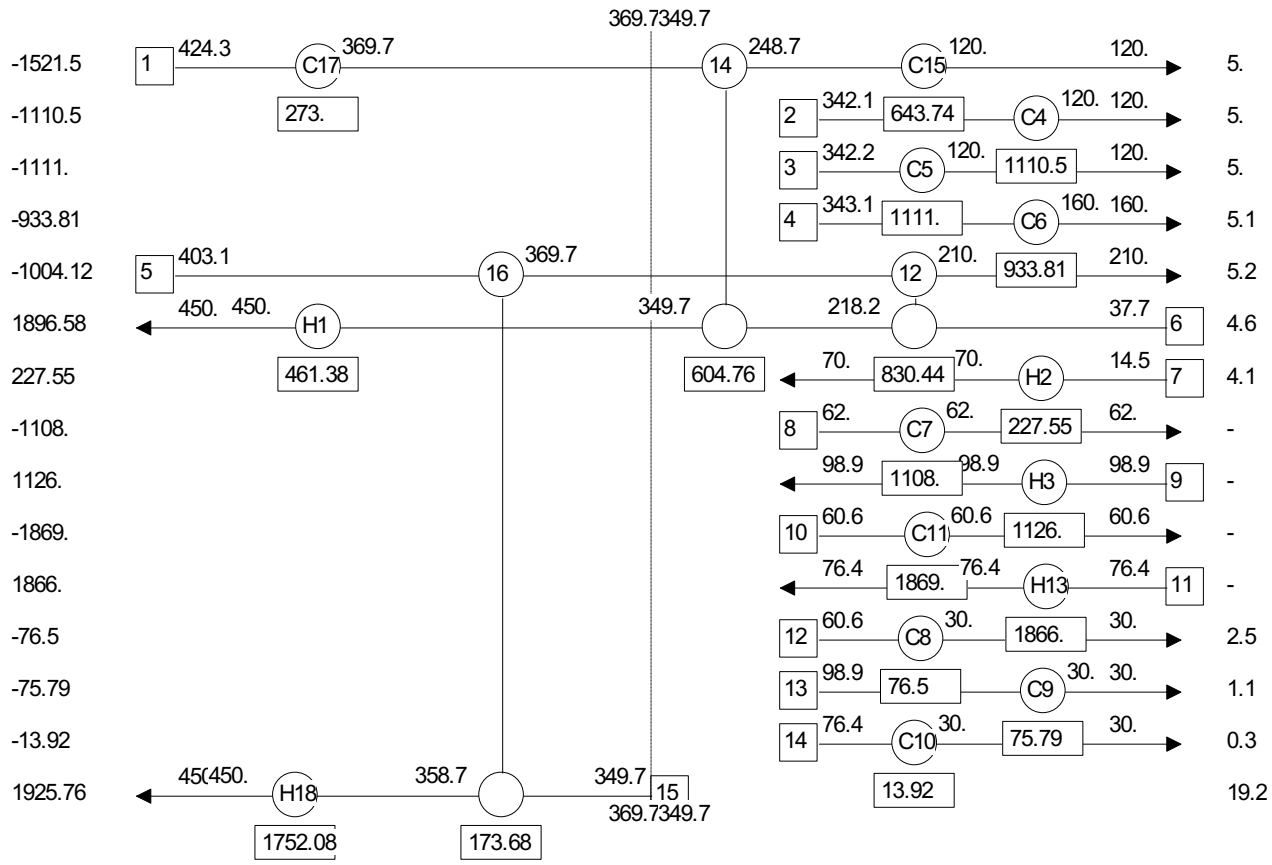

Fig. 3. HEN of methanol synthesis with $\Delta \mathrm{T}_{\min } 20 \mathrm{~K}$

Table 2. Heating and cooling duty

\begin{tabular}{lccc}
\hline & $\boldsymbol{\Delta} \mathbf{T}_{\min } \mathbf{1 0} \mathbf{K}$ & $\boldsymbol{\Delta} \mathbf{T}_{\min } \mathbf{1 5} \mathbf{K}$ & $\boldsymbol{\Delta} \mathbf{T}_{\min } \mathbf{2 0 ~ K}$ \\
\cline { 2 - 4 } Heating duty $(\mathbf{k W})$ & 1838.46 & 1889.46 & 1940.46 \\
Cooling duty $(\mathbf{k W})$ & 3620.71 & 7189.26 & 3722.71 \\
\hline
\end{tabular}

As could be seen from the HEN diagrams of $\Delta \mathrm{T}_{\text {min }} 10,15$ and $20 \mathrm{~K}$, the pinch temperature obtained were $359.7,364.7$ and $369.7 \mathrm{~K}$ respectively. Based on Table 2, it could be seen that the heating duty, cooling duty and maximum energy recovery values all strongly depended on the value of $\Delta \mathrm{T}_{\text {min. }}$. The network on the above pinch region contained two hot and two cold streams, which shown that streams 5 and 6 were linked. Both of said streams had fulfilled the criteria of the heat capacity flowrate $\left(\mathrm{Cp}_{\mathrm{oud}}>\mathrm{C} \mathrm{p}_{\mathrm{wax}}\right)$. Hence, there was a heat exchanger in stream $6\left(\mathrm{H}_{\mathrm{i}}\right)$ and stream $5\left(\mathrm{H}_{\mathrm{s}}\right)$. While in HEN with $\Delta \mathrm{T}_{\min } 20 \mathrm{~K}$ (Figure 4), there was a heat exchanger in stream $1(\mathrm{C} 17)$ which was functioned to cool the process.

Whereas for the network below the pinch region contained 8 hot and 2 cold streams, with some streams were of latent heat. The only stream that managed to fulfill the feasibility

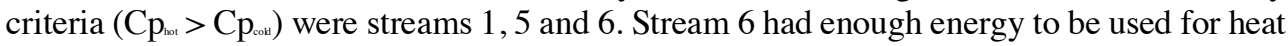
recovery in stream 1 and 5. While latent heat could not be used to recover other streams, due to the fact that it would cause the crossing of temperature across the streams. In total, there were 13 heat exchangers located in the below pinch region, which consisted of 10 coolers and 3 heaters. 


\subsection{Economic analysis}

Table 3. Cost of HEN configuration on methanol synthesis

\begin{tabular}{|c|c|c|c|c|c|}
\hline & \multirow{2}{*}{$\begin{array}{l}\text { Operating } \\
\text { cost }(\$ / y)\end{array}$} & \multicolumn{2}{|c|}{ Capital cost $(\$ / y)$} & \multicolumn{2}{|c|}{ Total cost } \\
\hline & & $\begin{array}{c}\text { Original } \\
\text { HEN }\end{array}$ & $\begin{array}{c}\text { Pinch tech } \\
\text { HEN }\end{array}$ & $\begin{array}{c}\text { Original } \\
\text { HEN }\end{array}$ & $\begin{array}{c}\text { Pinch tech } \\
\text { HEN }\end{array}$ \\
\hline $\begin{array}{c}\Delta T_{\min } 10 \\
K\end{array}$ & 2.729 .590 & 645.600 .000 & 576.400 .000 & 648.329 .590 & 579.129 .590 \\
\hline$\underset{\mathbf{K}}{\Delta \mathbf{T}_{\min }} \mathbf{1 5}$ & 2.780 .590 & 679.100 .000 & 584.000 .000 & 681.880 .590 & 586.780 .590 \\
\hline$\underset{\mathbf{K}}{\Delta \mathbf{T}_{\text {min }} \mathbf{2 0}}$ & 2.831 .590 & 653.100 .000 & 626.400 .000 & 655.931 .590 & 629.231 .590 \\
\hline
\end{tabular}

Table 3 compared the cost required on methanol synthesis with the orginal heat exchanger network configuration and the configuration after pinch analysis. The capital cost was calculated using the following equation:

$$
C=a+b A^{c}
$$

where values of $\mathrm{a}, \mathrm{b}$ and $\mathrm{c}$ were parameters based on the type of heat exchanger. Calculation was done automatically using the HINT software. It could be concluded from the results that the total cost of HEN configuration after the pinch analysis for all $\Delta \mathrm{T}_{\min }$ were lower compared to the original HEN configuration. Therefore, it could be said that there was energy conservation in the process, as the number of heater and/or cooler installation were less than before. With less heat exchanger, the capital cost would also decrease. Based on Table 3, the lowest total cost was obtained from HEN configuration with $\Delta \mathrm{T}_{\min } 10 \mathrm{~K}$.

\section{Conclusion}

The heating and cooling duty were dependent and directly proportional to the $\Delta \mathrm{T}_{\text {min. }}$. The total cost of methanol synthesis with HEN configuration using pinch technology were lower compared to the original configuration. The optimum $\Delta \mathrm{T}_{\text {nin }}$ was estimated to be $10 \mathrm{~K}$, which generated operating cost $\$ 2.729 .590 /$ year and capital cost $\$ 579.129 .590 /$ year. 


\section{References}

Authors should use the forms shown in Table 3 in the final reference list.

Table 3. Font styles for a reference.

\begin{tabular}{|c|c|}
\hline Element & Style \\
\hline Authors & $\begin{array}{c}\text { Reference Body } \\
\text { (Initials followed by last name) }\end{array}$ \\
\hline Journal title & $\begin{array}{c}\text { Reference Body } \\
\text { (Abbreviated) }\end{array}$ \\
\hline $\begin{array}{c}\text { Book title, Proceedings } \\
\text { title }\end{array}$ & Reference Body - Book/Proceedings title \\
\hline Volume number & Reference Volume Bold \\
\hline Page number & Reference Body \\
\hline Year & $\begin{array}{c}\text { Reference Body } \\
\text { (In brackets) }\end{array}$ \\
\hline
\end{tabular}

Here are some examples:

1. NASA, What is the Greenhouse Effect? (2020). Accessed on 24 June 2020 from https://climatekids.nasa.gov/greenhouse-effect/

2. EDF, Methane: The Other Important Greenhouse Gas. (2020). Accessed on 24 June 2020 from https://www.edf.org/climate/methane-other-important-greenhouse-gas\#: :text=If $\% 20$ methane $\% 20$ leaks $\% 20$ into $\% 20$ the, greenhouse $\% 20$ gas $\% 2 \mathrm{C} \% 20$ like $\% 20$ carbon $\% 2$ 0dioxide.

3. Choudhary, V. R., Patil, V. P., Jana, P. and Uphade, B. S, Nano-gold supported on $\mathrm{Fe}_{2} \mathrm{O}_{3}$ : a highly active catalyst for low temperature oxidative destruction of methane green house gas from exhaust/waste gases. Applied Catalysis A: General 350, 186-190. 3 (2008)

4. Dalena, F., Senatore, A., Marino, A., Gordano, A., Basile, M. and Basile, A, Chapter 1Methanol Production and Applications: An Overview, in Methanol. Elsevier: Science and Engineering, 3-28 (2018)

5. Azadi, M., Tahouni, N. and Panjeshahi, M. H, Energy conservation in methanol plant using CHP system. Applied Thermal Engineering 107, 1324-1333 (2016)

6. Hall, S. Energy Conservation, in Branan's Rules of Thumb for Chemical Engineers, $5^{\text {th }}$ ed (2012)

7. Riyanto, T., Putri, F. M. Y. and Widayat, Heat integration analysis of preliminary plant design of glycerol conversion into propylene glycol. International Journal on Engineering Applications 7, 204-209 (2019)

8. Kijevcanin, M., Djordjevic, B., Ocic, O., Crnomarkovic, M., Maric, M. and Serbanovic, $\mathrm{S}$, Energy and economy savings in the process of methanol synthesis using pinch technology. Journal of the Serbian Chemical Society 69, 827-837 (2004)

9. F. De Lillo, F. Cecconi, G. Lacorata, A. Vulpiani, EPL, 84 (2008)

10. L. T. De Luca, Propulsion physics (EDP Sciences, Les Ulis, 2009)

11. G. Plancque, D. You, E. Blanchard, V. Mertens, C. Lamouroux, Role of chemistry in the phenomena occurring in nuclear power plants circuits, in Proceedings of the International Congress on Advances in Nuclear power Plants, ICAPP, 2-5 May 2011, Nice, France (2011) 